\title{
ALGUNS CRITÉRIOS PARA A TECNOLOGIA MORFOSSINTÁTICA
}

\author{
SOME CRITERIA FOR MORPHOSYNTACTIC TECHNOLOGY
}

\author{
Marcelo CAETANO \\ Universidade do Estado do Rio de Janeiro e Academia Brasileira de Filologia \\ marcelomcaetano@gmail.com
}

\begin{abstract}
Resumo: Os estudos de morfossintaxe portuguesa ainda padecem de certa falta de precisão terminológica. Isso é ocasionado em grande parte pela confusão na demarcação dos pontos investigativos de que deve se valer. Este artigo propõe que se estabeleçam dois planos distintos: o plano do léxico e o plano da gramática. Esse binômio tem relação direta com a dicotomia paradigma e sintagma (cf. Saussure) e, assim como na aludida dicotomia, é preciso primeiramente que se estabeleça a aplicação de cada parte do par para, só então, criarem-se áreas de comum acordo que permitam as articulações pertinentes ao pesquisador. Por lidar com muitos ferramentais da língua, como flexões, classificações categoriais e gramaticais dos vocábulos, lexicologia, gramaticalização, formação de palavras, sistema e norma de uma língua, a morfossintaxe acaba ficando à mercê de muitos pontos obscuros, que devem ser constantemente debatidos. Como se trata de um dos pontos fundamentais da deriva (cf. Sapir) de uma língua, a morfossintaxe não pode se desvincular de um estudo cada vez mais crítico e reflexivo, capaz de lhe fornecer material tecnológico para a construção de uma nomenclatura que reflita a importância desse estudo no imo do sistema de uma língua. A negligência com esses fatores põe em xeque até mesmo a possibilidade de demarcação de um idioma que, como comprova a linguística histórica e a filologia, transforma-se, no tempo e no espaço, em outros idiomas.
\end{abstract}

Palavras-chave: Léxico. Gramática. Sintagma. Paradigma.

Abstract: Portuguese morphosyntax studies still suffer from a lack of terminological precision. This is caused by the confusion in the demarcation of the investigative points that should be used. This paper proposes to establish two distinct plans: the lexical plan and the grammar plan. This binomial is directly related to the dichotomy paradigm and syntagma (cf. Saussure), and first of all it is necessary to establish the application of each part of the pair so that the common areas canallow the relevant joints to the researcher. For handle many language tooling, such as inflexion, categorial and gramatical ratings, lexicology, grammaticalization, word formation, system and standard of a language, the morphosyntax ends up in front of many obscure points, which must be constantly debated. As it is one of the fundamental points of the drift (cf. Sapir) of a language, the morphosyntax can not detach itself from an 
increasingly critical and reflexive study, capable of providing it with technological material for the construction of a nomenclature that reflects the Importance of this study in the center of the system of a language. The neglect of these factors creates doubts even in the possibility of demarcation of a language, as evidenced by historical linguistics and philology, and how it becomes, in time and space, another languages.

Keywords: Lexicon. Grammar. Syntagma. Paradigm.

\section{Introdução}

Lançamos como premissa maior de nossa elaboração uma estratégia de divisão investigativa, para o concernente à estrutura e formação das palavras, cujo embrião é tão só uma realidade linguística bipartida. De um lado, o plano do léxico da língua (neste momento, entendemos "léxico" stricto sensu, isto é, as palavras nocionais). Do outro, o plano da gramática daquela língua (o que entendemos como aquele em que há itens instrumentais, gramaticalizados ou em gramaticalização), em que, por razões sintáticas, na maioria das vezes (embora se saiba da relevância das razões ideológicas, atrativas ou afetivas da concordância ad sensum, enfim), as palavras se ajustarão a certos ditames intrínsecos à estrutura gramatical, de significação precipuamente interna.

Apenas para tecermos uma primeira impressão geral, e didaticamente expositiva, o Plano do Léxico será por nós considerado como aquele cuja consequência ulterior é o dicionário. Daí podermos, numa espécie de metalepse designativa, chamá-lo de Plano do Dicionário.

O Plano da Gramática será, por seu turno, no que tange aos aspectos de morfossintaxe, considerado, para esta finalidade, como aquele em que se darão as concordâncias verbal e nominal (adstritos ao conceito de flexão), inclusive (ou exclusivamente) no que tange à categoria de flexão, o que não necessariamente ocorre por meio do veículo de flexão.

Numa abordagem mais ampla, esse conceito se estenderá ao que abarca a necessidade de categorias gramaticais. Será, também, o que, por razões didáticas, fundiremos ao conceito de plano do texto (ou de contexto), estando mais ligada a este conceito a ideia de movimentações semânticas, ou espécies de aquisição de sentido, expressões que utilizamos para evidenciar as 
vantagens de um critério semântico; porém, do mesmo modo, as desvantagens de um critério que seja apenas semântico.

Voltemos brevemente a um ponto observado no parágrafo anterior. Vemos que, numa análise que não se pretende exclusivamente do campo da Linguística, mas, antes, da Gramática, tal distinção - categoria versus veículo será indispensável para casos em que, por veículo de derivação se consegue a satisfação da categoria de flexão (ex.: Imperador/Imperatriz; Galo/Galinha etc.). Nesse caso, observamos que a derivação, por exemplo, pode ser encarada como um processo (de formação de palavras) assim como, talvez simultaneamente a isso, um veículo (de formação e/ou atualização de palavras).

Ocorre que, como vimos, a categoria diz respeito a necessidades de funcionamento interno da língua, como o fato de, em português (o que não acontece, por exemplo, em inglês), haver necessidade de flexão nominal de todos os membros do sintagma nominal (determinantes e determinados).

Assim, um caso em que a derivação tenha servido apenas como veículo para ajustes categóricos da língua (como é a flexão) deverá ser considerado pertencente ao plano da gramática, antes do mais, não ao do dicionário (não obstante este arrolar tal idiossincrasia em seu rol). Isso nos permitirá rever com matéria-prima nova (e preciosa) a discussão em torno do conceito de grau: flexão ou derivação?

Isso se pode extinguir sob o prisma dos conceitos maiores: categoria ou veículo? Produção de entradas ou ajuste destas? Já se adiante isto: o grau é uma categoria de flexão (porque é necessário na língua conquanto não dê nova entrada léxica) com veículo (via) de derivação (porque utiliza sufixos).

Como sabemos, cada um desses dois planos (o do dicionário e 0 da gramática) tem por objeto de estudo e análise conceitos perfeitamente distinguíveis, embora não excludentes, unidos, por fim, sob um ponto de vista mais amplo, qual seja o da análise da estrutura e formação da Palavra. Já vamos, aqui, esboçando o porquê de termos adotado essa como expressão "neutra" ou "acima" dos dois planos distintos de análise por que propugnamos. 
É exatamente da confusão entre esses planos (mas não só daí) que, por via de regra, muitos dos problemas hoje recorrentes na análise da estrutura das palavras vêm a lume.

A questão que parece aqui vir esboçando-se - e em que de pronto se porá termo - é: seriam as palavras flexionadas de um mesmo radical (ou de um mesmo tema) consideradas uma só palavra, ou, ao invés disso, devem ser encaradas como várias palavras, tantas quantas sejam as flexões ocorrentes?

E, daí, surge outra questão: até que ponto interferirá aquela outra nos estudos da morfologia?

Conforme veremos, é exatamente na base da distinção sugerida há pouco que se calca, também, o ponto de partida de nossos estudos aqui apresentados, que procurarão desbastar as imprecisões advindas da falta de um estabelecimento claro de critérios norteadores de cada classificação em que se empenhe o autor.

Embora venhamos a lançar mão de toda uma gama de termos já utilizados alhures por inúmeros autores, definiremos, aqui - conforme apregoamos ser evidentemente necessário -, a tessitura, a abrangência conceitual, de modo a que não haja, a posteriori, o problema contra o qual vimos lutando; qual seja, a imprecisão terminológica e conceitual no seio do estudo ora enfocado.

Não pretendemos dar cabo de um assunto que está, sempre, a merecer reformulações. Queremos, muito em vez disso, apresentar uma modesta contribuição, lançar sementes que venham a apontar alguns dos prejuízos oriundos de uma análise negligente em certos parâmetros, nesse tão importante campo da análise descritiva do idioma.

\section{Aprofundamento sobre conceitos fundamentais}

Vamos aos conceitos-chave.

Entendemos por lexema, numa primeira instância, cada entrada no dicionário, cada verbete deste. Já de pronto estamos promovendo liame entre esses dois conceitos: Lexema-Plano do Dicionário. 
Deve-se fazer a ressalva de que, no entanto, haverá casos, não poucos, numa análise mais apurada, em que a noção de verbete deve desligar-se da de lexema, pois que um lexema pode não vir na cabeça do verbete, sendo, ainda assim, um lexema. Sem contar que um verbete poderá não constituir lexema, mas mero aporte gramaticalizado (ou em gramaticalização).

É o lexema uma entidade abstrata, pertencente ao plano paradigmático(cf. Saussure) da língua, e deve ser encarado em confronto com a sua entidade coetânea, porém concreta, que é o vocábulo, consubstanciado, por assim dizer, no texto (contexto) ou na situação, o que vem a constituir o plano sintagmático (cf. Saussure).

A escolha do lexema, enquanto verbete - que, geralmente, o será -, é, assim, arbitrária, devendo-se aplicar a técnicas lexicográficas, a que estará restrita. Um exemplo é o caso de, em português, arrolar-se o verbo no dicionário pelo seu infinitivo, o adjetivo pelo seu masculino singular.

Assim, o falante de uma língua deve dispor para si, a fim de obter as competências falante, leitora e escrevente completas, daquelas mesmas técnicas, por meio das quais procede à consulta de um dicionário.

No fim das contas, há, aqui, uma prova, dentre inúmeras outras, de por que se deve separar o conceito de lexicologia do de lexicografia, pois que neste último devem estar presentes preocupações com o método de inventariação, arrolamentoe confecçãodas dicções (entidades léxicas e morfêmicas) da língua. A questão de serem inventariados os morfemas gramaticais nos parece, portanto, apenas de valor secundário à lexicologia, não o sendo, contudo, à técnica lexicográfica.

Em Problemas de linguística descritiva, Matoso Câmara Jr. discute algumas dessas escolhas. Transcrevemos dois trechos que nos parecem mais ilustrativos, na medida em que põem em xeque a arbitrariedade lexicográfica (que não está sendo por nós combatida, ressalve-se):

A segunda decisão é a consequência pragmática desta nova atitude doutrinária e importa numa modificação substancial na técnica de fatura de dicionários. Consiste em entrar nos verbetes dos dicionários com um tema teórico que corresponde ao da forma feminina singular, para os nomes, e, nos verbos, em indicar o verbete pela 2. pessoa singular do indicativo presente, em vez de fazê-lo com o infinitivo. Este, como forma 
arrizotônica (ou de radical átono), é, com efeito, irrelevante para nos dar a conhecer a genuína vogal radical. Ela só aparece quando tônica, porque, como já vimos, é então que funciona o quadro pleno das vogais portuguesas sem qualquer neutralização das suas oposições fundamentais. (CÂMARA JR., 1997, p. 58)

Uma descrição genuinamente sincrônica tem de partir dos temas teóricos (que devem ter entrada nos dicionários, em vez da inexpressiva forma singular). A forma singular pode então ser explicada por algumas regras morfofonêmicas: 1) -õe para -ão (mudança de tema e alternância do /o/ tônico para /a/); 2) -ãe para -ão (mudança do tema); 3) -ão (sem mudança morfofonêmica). (CÂMARA JR., 1997, p. 61)

A expressão vocábulo parece-nos mais adequada às diversas manifestações morfossintáticas de um dado lexema. E, conforme tenha esse vocábulo significação externa ou interna (nocional ou gramatical), chamar-lheemos, respectivamente, se for preciso, vocábulos semânticos ou vocábulos gramaticais, não desprezando, assim, a própria semântica.

Com efeito, ambos os tipos de vocábulos possuem, atendendo a um plano de análise superior, seus lexemas. Apenas o que entendemos como morfemas gramaticais, tenham eles função externa ou interna (ou apresentem eles peremptoriedade em uma dessas), por serem entidades de forma obrigatoriamente presa (como o eram as desinências número-casuais latinas, por exemplo), não possuirão lexemas, ainda que possuam, num dicionário, entradas ou verbetes.

Assim, ligamos intimamente Vocábulo a Plano da Gramática lato sensu (funcionamento do idioma em si) ou Plano do Texto, já que aquele conceito o será no resultado da atualização concreta do lexema (que é abstrato).

Seria mais acertado, como o fizemos há pouco, falarmos em função externa, em vez de em significação externa, pois que, por exemplo, as noções que advêm com os substantivos abstratos não são noções provenientes do "mundo dos objetos" (cf. Cassirer), mas, antes, o são da nomeação prévia de outras qualidades, ações, estados subjetivos. E, apesar disso, sua função de nomear aspectos correlacionados mais imediatamente com esse "mundo dos objetos" permanece. Assim, houve como que primazia da categoria profunda de função sobre a de significação. 
Entendemos como categoria profunda o eixo paradigmático ulterior e/ou prévio da língua, como, por exemplo, a questão que aqui se pôs: significação ou função? No caso dos adjetivos, advérbios e substantivos abstratos, por exemplo, quer-nos parecer que a categoria profunda que os governa é a de função, não a de significação, que, esta última, está calcada no conceito aristotélico.

Antoine Meillet (1923) dá-nos a distinção para Nome como sendo aquilo que indica coisas, sejam estas concretas, sejam abstratas: pierre, table, vert, verdeur, bonté, cheval. Dá-nos também distinções interessantes sobre a estrutura "concreta" e a "abstrata" da palavra, tratando do assunto sob o ângulo da função dessas palavras: externa (nocional) ou interna (gramatical).

Com aquela distinção, parece-nos estar sendo vedada uma confusão muito comum que se faz amiúde, que é aquela que diz respeito a se classificarem como morfemas stricto sensu (isto é, num conceito emparelhado com o de morfema de Vendryès) elementos tais como preposições, artigos, pronomes, conjunções, pela simples circunstância de não possuírem, em princípio, o que chamam de significação externa. Houve, portanto, convergência dos critérios semântico, gramatical (funcional), formal e estrutural, que, certamente, não poderiam ter sido, aqui, aplicados à formulação de um só conceito classificatório, pois criam um emaranhado que não resiste à investigação mais profunda.

Quanto a esse ponto, àqueles que porventura classifiquem as preposições daquela forma por terem elas provindo, em aspecto sintático, das declinações latinas, lembramos-lhes, mais uma vez, que, em que pese à autenticidade dessa afirmação, as desinências número-casuais latinas eram presas aos radicais, o que não ocorre com a preposição. Portanto, o papel sintático das preposições é dar - assim como o era com as desinências latinas - muitas das subordinações sintagmáticas, não deixando de haver, com isso, diferença formal entre esses dois mecanismos aqui debatidos.

É somente num contexto que há de ocorrer a atualização, seja ela referencial (intelectiva), seja ela expressiva, apelativa, enfática, pragmática, discursiva, seja ela enfocada do ponto de vista da estrutura (que é, aqui, o que 
nos diz respeito mais de perto) de uma daquelas unidades abstratas de que se empenham os dicionários.

O próprio conceito atualização merece discernimento. Se diz respeito ao vocábulo, está referindo-se a quaisquer formas de "ajuste"- seja semântico, seja flexional etc. - desse vocábulo à realidade - seja ela própria semântica, seja gramatical etc. - do contexto em que se acha.

Se diz respeito ao lexema, que é, como dissemos, unidade abstrata, deverá ser visto como atinente tão só ao campo da estrutura. Isto é, a atualização de um lexema é apenas o conjunto de procedimentos por meio dos quais aquele lexema poderá, posto que virtual, figurar (concretamente, pois) num dicionário.

Um exemplo esclarecerá. Não podemos dizer que seja atualizada a forma (mínima) cas-, tanto que poderá estar-se referindo a um substantivo (as minhas casas) quanto a um verbo (Tu casas amanhã). Dessa maneira, será que a aposição de uma vogal temática, que é, pois, elemento atualizador, deixará inequívoco a que lexema se reporta aquele radical, por si mesmo, então, forma apenas latente? Em todo o caso, já foi esta uma atualização em nível de lexema.

Se essa mesma entidade (casa) aparece isolada, não nos é possível depreender de que lexema se trata: se do que diz respeito ao substantivo ou se ao verbo. O texto, portanto - uma atualização discursiva concreta, em nível de vocábulo -, nos permitirá desfazer aquele impasse.

Assim, o lexema, presente que está na categoria do sistema linguístico (a estrutura paradigmática do signo), em si mesmo virtual (e, potencialmente, sob aqueles pontos de vista - semântico, formal, funcional -, muito amplo) há de obter efeitos (intelectivos ou expressivos ou funcionais ou de estrutura e forma, repita-se) também específicos mediante seu emprego no enunciado ou no texto. São níveis diferentes, já aqui, de atualização.

Por isso julgamos necessária a mesma distinção que se faz, apenas para termos um exemplo de acesso imediato, na estilística: a pertinência de um signo, por um lado, à estrutura do código (eixo paradigmático), e, por outro, à 
estrutura da mensagem (eixo sintagmático), o que está patente e passível de decomposição, sem maiores elucubrações.

A estilística lidará com a análise dos meios, latentes ou atualizados, sob o ponto de vista da expressão-impressão (subjetividade emotiva/apelativa); a morfologia deverá ver claramente, mutatis mutandis, a mesma distinção relativa aos meios (da estilística), quanto aos campos de atuação de análise da forma (objetividade intelectiva/represen-tativa). Vale mais uma vez ressaltar que estamos adstritos à tripartição bühleriana, que tantas vezes merece ser evocada: Representação, Apelo e Manifestação Psíquica.

Pode-se tirar uma primeira conclusão, assaz nítida: a unidade de análise no texto não é o lexema, mas o vocábulo. Por isso diremos, só para ilustrarmos com um exemplo, que revisito é, no plano do vocábulo, morfossintaticamente, um verbo (em princípio só o contexto o poderá ter determinado) no presente do indicativo, primeira pessoa do singular (com desinência número-pessoal “-o”), enquanto, na análise do lexema (revisitar), veremos um verbo derivado (do morfema lexical visit-, cujo lexema motivador deve ter sido visitar).

Parece-nos confusa a análise que constate, a um só tempo: re-, prefixo; visit-, radical; -o, desinência número-pessoal. Confusa porquanto pouco científica, de acordo com o que mostramos, já que mistura, numa única análise, métodos e objetivos de análises diferentes: a do Plano do Dicionário (lexema

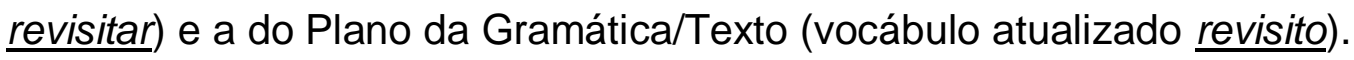

Quando Varrão opôs a derivatio naturalis (correspondente à flexão) à derivatio voluntaria (correspondente à derivação), já estava dado um importante passo rumo à discussão a que agora damos ensejo. Assim, o conceito de derivação está circunscrito, quase sempre, ao de lexema, e é secundário, se nos quisermos ater ao repertório a que temos acesso pela língua vigente; o de flexão, por seu turno, deve estar vinculado ao de vocábulo, atualizando estruturalmente aquele lexema, algo ideal.

Sabemos que, também com Dionísio da Trácia, tais noções foram discutidas sob os conceitos de ptosis, ou caso, e êidos, ou tipo, respectivamente a flexão e a derivação. 
Herculano de Carvalho (1973) adota a expressão palavra semântica para o que chamamos lexema, e palavra léxica para o que chamamos vocábulo. Assim, a palavra semântica seria a unidade abstrata, que se manifesta de uma ou diversas formas como palavras léxicas.

Embora se trate, grosso modo, apenas de diferença de terminologia, porquanto os conceitos que envolvem os nomes sejam muito similares, o inconveniente dessa nomenclatura do ilustre filólogo e linguista português calca-se na circunstância de que o critério para se estabelecer a existência de um lexema não é apenas semântico (como é a sugestão imbricada no termo por ele adotado).

Ademais, ao falar em palavra léxica, parece-nos estar esta expressão mais conjugada àquilo por que propugnaremos quando da tentativa de esboçar os critérios do que venha a ser um lexema: tudo o que constitui o léxico ideal da língua, seja em sua parte que permaneça aberta, seja na que permaneça fechada.

Muito embora não haja, de per si, compromisso líquido e evidentemente apreensível, quando da formulação de um termo, entre o conceito intrínseco a esse termo e palavras assim digamos "expressivas" que o venham a explicitar logo numa primeira visão que nele se lance, sob a vestimenta de uma expressão "bem escolhida" ou "bem fornida", ou ainda - com pretensão "perfeita".

Tirante tais digressões, de somenos valor, foi mesmo do ilustre mestre que retiramos a expressão palavra quando de um tratamento nos níveis da estrutura e da formação, pois, como se vê, é ele quem abarca as duas noções - a que chamamos lexema e vocábulo - sob a mesma expressão: a Palavra.

$\mathrm{Na}$ verdade, mais apropriado ao estudo da morfossintaxe será, como dissemos pouco acima, a apreensão dos vocábulos, ficando o estudo dos lexemas mais restrito, grosso modo, à parte específica à formação de novas palavras - isto é, de novas entradas no dicionário, pois naturalmente, o significado de visitar é distinto do de revisitar.

No entanto, impõe-se elucidação de outro pormenor: não se deve vincular necessariamente a noção de lexema, enquanto verbete, à de significado, isto é, 
não se deve dizer que, por exemplo, visitar e revisitar sejam dois lexemas apenas por apresentarem significados distintos. Se 0 fizéssemos, concluiríamos, naturalmente, que palavras sinônimas constituem um mesmo lexema (por terem o mesmo significado) embora seus radicais sejam completamente diversos. Tal conclusão é tão falsa quanto o são as premissas - baseadas tão só no âmbito semântico - que a possibilitaram.

Lexema é, repita-se, a princípio, cada nova entrada utilizada na língua, cujo reflexo será o dicionário. Aproveitamos o ensejo para lembrar que, mesmo numa série sinonímica (ou família ideológica), há matizes semânticos distintos, grandes ou pequenos, que, num ou noutro caso, servem de separar consideravelmente um lexema de outro (cf. casa, lar, residência, abrigo, esconderijo etc.).

Há, também, nos dicionários, como se poderá observar mediante pesquisa, casos em que entram algumas variantes fonéticas (e,muitas vezes, gráficas) de um mesmo lexema, como nos casos sincréticos (cf. assobiar e assoviar, réptil e reptil etc.).

Assim, o lexema é tão só uma unidade ideal, de um ou mais significados, ao passo que o vocábulo é a unidade funcional que concretiza o lexema, dando-Ihe um sentido específico.

\section{Considerações finais}

Por isso o termo morfossintaxe é o de melhor encaixe para o estudo da estrutura da palavra (morfologia parece-nos mais ligado à formação de palavras), pois que a atualização mórfica, embora parta de uma entidade abstrata, o mais das vezes, se dá por causa da sintaxe (ou do eixo sintagmático).

Mesmo quando se formam novas palavras, algo ligado em princípio ao lexema (o que, aparentemente, colocaria o texto - a situação e o contexto, outrossim - num segundo plano), ainda assim não é raro que devamos observar de que ponto real, isto é, atualizado naqueles patamares de que falamos (atualização esta ocorrida mercê de uma situação ou de um contexto), partiu, enfim, a motivação do falante para a criação da nova palavra. 
Quer isto dizer que, ainda quando estivermos lidando com a formação de palavras, o que toca mais fortemente o lexema, repita-se, é preciso ver-se, dentro de uma grande limitação - de que devemos ter consciência -, qual a intenção real havida por detrás daquela nova entidade que surge (um critério "semântico-estilístico-discursivo", em que se enfoca o "sujeito intencional"). Isto é, quais os mecanismos através dos quais se pôde ela manifestar como vocábulo, para, desse ponto, poder-se partir à análise formal desse vocábulo, indo-se, enfim, ao seu lexema, tal como se apresenta atualmente sob o crivo da técnica lexicográfica.

llustramos com alguns casos derradeiros.

Há o verbo bancar e o verbo desbancar. De um ponto de vista restrito, diríamos que, por estarmos lidando com lexemas, bancar é primitivo, e desbancar é derivado; em outros termos, àquele se antepôs um prefixo (des-), dando-se origem a este.

Se se for em busca do elemento humano, criador por si só de inumeráveis situações, fomentadoras de outros inumeráveis ensejos e oportunidades à criação de palavras, poderíamos achar, supor, quase a nosso bel-prazer, que, embora houvesse aquele verbo primitivo (bancar), não é dele que provém efetivamente desbancar, mas possuem, ambos, em vez disso, um lexema de origem comum: banca.

Toda essa análise deve ser enquadrada, obviamente, apenas aos segmentos dos verbetes em que um destes verbos seja antônimo do outro, pois que, além desses, apresentam significados que seriam díspares, não possibilitando este nosso questionamento.

Por essa análise morfossintática, bancar seria derivado de banca, assim como desbancar o seria, também.

Outro exemplo, talvez um tanto mais claro, seria o dos adjetivos temido e destemido. Ora, já numa primeira lançada de olhos se verá que, em termos semânticos, "temido" é "quem causa temor a outrem", pelo que "destemido" deveria ser, já que supostamente seria o acréscimo do prefixo de negação des, "quem não causa temor", o que não é verdadeiro (cf.: destemido = "quem não possui temor de outrem"). Se são palavras cognatas? Naturalmente, mas 
ambas de um mesmo radical: -tem-. Assim devemos proceder, em vez de traçarmos que de "temido" (palavra primitiva) veio, por derivação, "destemido" (palavra derivada). Se não nos dispusermos ir ao abstrato, algo falho sempre poderá sobrevir.

Por uma análise meramente mórfica isso seria inviável. Quer-nos parecer que essa análise a que procedemos está mais próxima da lei dos constituintes imediatos, pois que teria sido desprezada, em primeira instância, até por um desconhecimento por parte do falante, a existência de um verbo (já formação derivada ela própria), partindo, sim, à "raiz" primeira que àquele mesmo verbo "primitivo" deu guarida.

Aqui podemos incluir palavras como: tronar/destronar,telhar/destelhar, frutar/desfrutar, cujos lexemas comuns seriam, respectivamente, trono, telha e fruta.

Já se pode tirar uma conclusão desse passo: como nos parece muito difícil (e mesmo pretensioso) achar que seríamos capazes de descrever, num vocábulo (ou lexema), a fonte de motivação que o gerou, achamos que, em muitos daqueles casos, a análise deve ater-se ao constituinte imediato formal, em vez de ir ao, por assim dizer, lexêmico.

Devemo-nos, em outras palavras, ater àquele morfema-base (ou morfema constituinte); sendo que um dicionário nos dará muitos lexemas que serão uma como provacabal dos resquícios léxicos, queremos dizer, dos caminhos por onde passou aquela palavra posta, então, sob análise.

Por esse pressuposto, seriam desbancar, destemido, destronar, destelhar, desfrutar, de fato, derivados de bancar, temido, tronar, telha, frutar. Ou numa análise que, embora fira a lei dos constituintes imediatos, nos parece mais científica, constataríamos, dando guarida e reconhecimento à nossa limitação quanto a aspectos psicológicos, culturais etc. do falante - aspectos esses que o teriam motivado a tais ou quais formações -, que tanto desbancar, destemido, destronar, destelhar, desfrutar quanto bancar, tronar, telhar, frutar têm morfemas lexicais comuns, de onde partiram, no entanto, derivações diversas, além de atualizações nominais (com vogais temáticas nominais, morfemas caracterizantes): banc-, tem-, tron-, telh-, frut-. Essa análise dá conta 
de muitos supostos mistérios que nos querem fazer crer que rondam o terreno da morfologia.

\author{
banc-a tron-o telh-a (vogais temáticas nominais) \\ $\underline{\text { banc}}-a-r \quad \underline{\text { tron-a-r }}-\boldsymbol{\text { telh}}-\mathrm{a}-\mathrm{r} \quad$ (v.t. verbais + desinência $=$ \\ des-banc-a-r des-tron-a-r des-telh-a-r (prefixo $+[$ VERBO])
} [VERBO])

Podem alegar alguns que esse tipo de análise rompe a possibilidade de visão evolutiva da palavra.

Em primeiro lugar, como reconhecemos, indo-se a um dicionário, se poderá chegar a um possível - quase sempre apenas possível- elemento constituinte imediatamente derivante. Em casos de dúvida realmente muito grande quanto à motivação real do falante para dar ensejo àquela nova entrada, ou bem deve prevalecer a "lei do dicionário", ou bem não se poderá, realmente, dar conta de uma cadeia evolutiva, pois que, tolhidos por fatores além de nossas faculdades investigativas (a sociologia, a psicologia, a antropologia etc.), não se preverá de onde se derivou, de fato, a nova entrada que se estuda.

Este é um dos pontos básicos desta tentativa, que ora encerra o artigo presente.

\title{
Referências Bibliográficas
}

CÂMARA Jr. Joaquim Matoso. Dicionário de Linguística e Gramática. 8. ed. Petrópolis: Vozes, 1977.

CARVALHO, Herculano de. Teoria da Linguagem. Coimbra: Atlântica Editora, 1973.

MEILLET, Antoine. Linguistique historique et linguistique générale. Paris: Seuil, 1921. 